\title{
Pharmacological Emptying of the Stomach with Metoclopramide
}

\author{
T. HILARY HOWELLS, T. KHANAM, LOUIS KREEL， C. SEYMOUR, B. OLIVER, J. A. H. DAVIES
}

British Medical fournal, 1970, 2, 558-560.

\section{Summary}

This paper evaluates the use of metoclopramide (Maxolon) in emptying human stomach contents into the duodenum and beyond. $A$ method of quantitative assessment of content by barium swallow radiography is used in the study, and the method is recommended as a diagnostic manoeuvre in patients presenting for emergency surgery in whom the stomach content is in doubt. Oral metoclopramide was found effective in emptying stomachs challenged by water load, and the intravenous route has been found effective in emptying semisolid contents in emergency clinical situations. A radiographic scan of the resting stomach was made on patients waiting for routine surgery who had received a variety of common premedication; it was shown that significant residues occur.

We believe that metoclopramide deserves further investigation in order to exploit its potential in reducing the hazard of regurgitation and vomiting in patients requiring emergency anaesthesia and surgery.

\section{Introduction}

The full stomach has always been one of the dangerous problems confronting the anaesthetist during his management of patients presenting for emergency surgery. The simple expedient of waiting four hours from the last ingestion of food and drink is not relevant in major trauma, nor is it a reliable time lapse for even minor trauma.

The dangers can be partially overcome by emptying the stomach by suction or induced vomiting, but these methods are not reliable and are extremely distasteful to the patient. This paper investigates the value of the preanaesthetic assessment of the stomach content by barium swallow radiography as suggested by Elliott and Sheville (1968) and the value of the drug metoclopramide (Maxolon) in effecting pharmacological emptying of the stomach which contains aqueous residue. The study is extended to measure the resting gastric volume found in patients under the influence of several preanaesthetic medications and discusses the clinical application of metoclopramidc in anaesthesia.

\section{Royal Free Hospital, London N.W.3}

T. HILARY HOWELLS, M.B., F.F.A. R.C.S., Director, Department of Anaesthesia

T. KHANAM, M.B., F.F.A. R.C.S., Senior Registrar, Department of Anacsthesia

C. SEYMOUR, S.R.N., Anaesthetic Sister

New End Hospital, London N.W.3

LOUIS KREEL, M.D., F.F.R., Consultant Radiologist (now Head of Radiology, Clinical Research Centre, Northwick Park, Hai row HA1 3UJ)

Selly Oak Hospital, Birmingham 29

B. OLIVER, M.B., F.F.A. R.C.S., Senior Registrar in Anaesthesia

J. A. H. DAVIES, M.B., F.F.A. R.C.S., Consultant Anaesthetist

\section{Method of Study}

An outline of the method and purpose of the study was given and explained to each volunteer who took part in the early assessment and also to each individual patient in the clinical study. Before beginning the work the project was submitted to our Subcommittee on Ethics and Experimentation on Human Beings and received its approval.

\section{RADIOGRAPHIC ASSESSMENT}

The method has been fully described elsewhere (Kreel, Trott, and Howells, 1971) so that only a brief description is given. The quantity of gastric fluid was correlated with its surface area as shown. on a radiograph taken in the erect position at a fixed film-focus distance. This was done during routine barium meals in 20 fasting subjects for volumes varying between 25 and $250 \mathrm{ml}$. The surface area of the stomach shadow on the radiograph thus obtained was measured with a fixed arm planimeter. These values were then plotted against the corresponding volumes of ingested barium on semilogarithmic paper and a curve was drawn through the mean values. The curve so obtained was used for future estimations of gastric residue.

A subject requiring gastric volume estimation would then be given $12 \mathrm{ml}$ of barium to outline the gastric contents, and a radiograph would be taken in a similar manner to that previously mentioned. The shadow of the stomach on the radiograph was measured with the fixed arm planimeter, and this value was used to obtain an estimate of gastric volume by taking a reading from the graph of gastric volume against surface area. While recognizing that estimates of volume were related to twodimensional readings, it was nevertheless found that there was a fair correlation between the area of the gastric shadow and the volume drunk in all subjects.

\section{STOMACH EMPTYING}

In the present study 40 patients, both male and female, aged 16 to 60 who were judged fit and to be without neurological, cardiovascular, respiratory, or gastrointestinal disturbances, and who were admitted to hospital for routine surgery of body surface, were taken into the trial and allocated to four groups of 10. All patients received diazepam $20 \mathrm{mg}$ one hour preopcratively as the sole premedication and lay on the right side, apart from sitting for "erect" radiography. Each presented with overnight fasting stomach. During the four preoperative hours group 1 patients were given 1 litre of water to drink, group 2 patients were permitted unrestricted water drinking, group 3 patients continued total fasting in the routine manner, and group 4 patients were permitted unrestricted water drinking but additionally received $20 \mathrm{mg}$ of metoclopramide 30 minutes before anaesthesia. A $12-\mathrm{ml}$ barium swallow radiograph was taken in all cases and seen just before anaesthesia.

In the event of retention products being shown by $x$-ray examination the patients were anaesthetized, cricoid pressure being combined with the attendant precautions used for patients presenting with regurgitation risks. 


\section{Results}

Figs. 1-3 show radiographs of measured ingested water volumes. In assessing the radiographs of each patient we were able to allocate scores of content to the nearest unit of $25 \mathrm{ml}$.

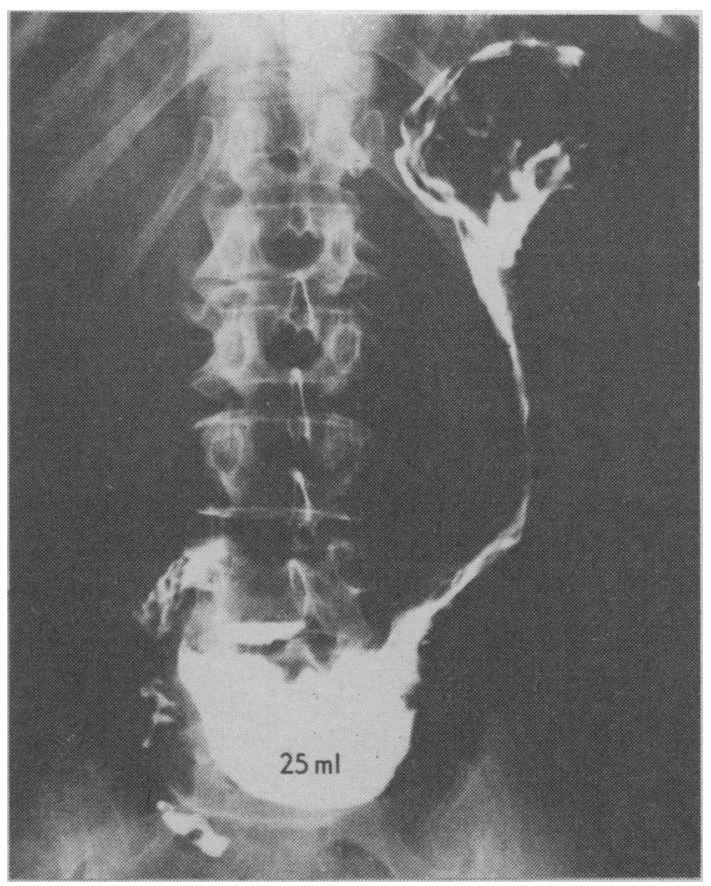

FIG. 1-Stomach previously proved empty by barium FIG. 1-Stomach previously proved empty by barium
outline, containing $25 \mathrm{ml}$ of water which had just been swallowed.

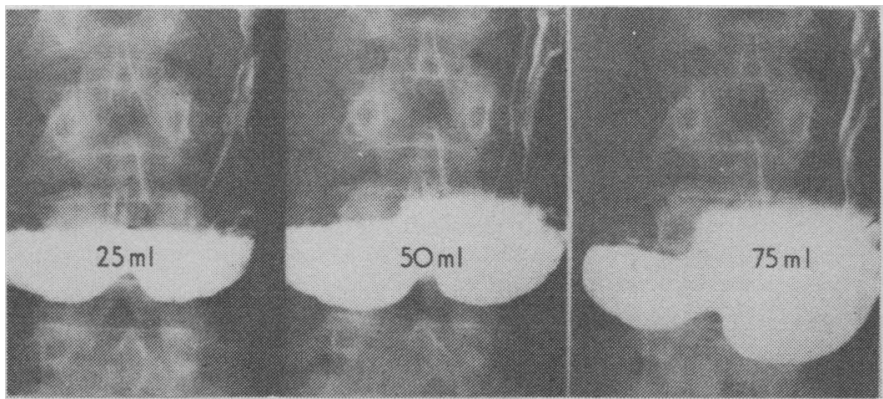

IIG. 2-Stomach of anuther paticnt with 25,50 , and $75 \mathrm{ml}$ of water.

It will be seen from Table I that the routine fasting patient may retain up to $25 \mathrm{ml}$ of fluid though $50 \%$ of subjects can be judged empty.

TABLE I-Gastric Volumes Remaining in the Four Groups

\begin{tabular}{|c|c|c|c|}
\hline Group 1 & Group 2 & Group 3 & Group 4 \\
\hline 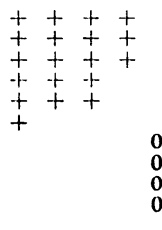 & $\begin{array}{lll}+ & + & \\
+ & + & \\
+ & + & \\
+ & & 0 \\
& & 0 \\
& & 0 \\
& & 0 \\
& & 0 \\
& & 0 \\
& & 0\end{array}$ & $\begin{array}{ll}+ & \\
+ & \\
+ & \\
+ & \\
+ & 0 \\
& 0 \\
& 0 \\
0 & 0 \\
& 0 \\
& 0\end{array}$ & $\begin{array}{l}+ \\
+ \\
+ \\
+ \\
+ \\
+\end{array}$ \\
\hline
\end{tabular}

$\dashv=25 \mathrm{ml}$

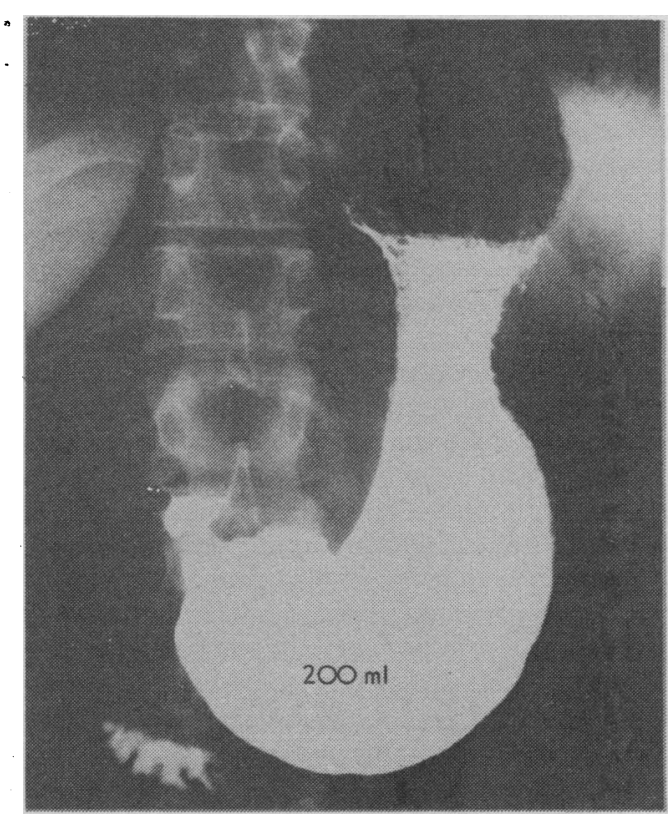

HIG. 3-Stomach with $200 \mathrm{ml}$ of watcr.

Four patients in group 1 had an empty stomach with the remainder retaining up to $100 \mathrm{ml}$-several of these patients complained that they drank more water than they wanted and a few patients enjoyed a diuresis.

Six patients in group 2 had an empty stomach while three retained up to $50 \mathrm{ml}$ of water. The average consumption in this group was $600 \mathrm{ml}$. In neither of these two groups was there any correlation between the amount drunk, any feeling of fullness, and the quantity of residue at the time of $x$-ray examination. Patients in group 4 showed results equal to those in the fasting patients in group 3.

\section{Further Study}

As half of the starved patients in the first study showed a stomach residue of $25 \mathrm{ml}$ we wondered what influence premedication has on the resting starved stomach, and we next made a radiographic scan of patients receiving a variety of common premedications. The patient selection and radiographic technique was the same as before. The results of the scan of 50 patients who received either nothing or one of four common premedications are given in Table II. On this occasion gastric volumes were calculated to the nearest $5 \mathrm{ml}$. It is seen that following any of these premedications some stomach residue may be found and that in the absence of any drug the fasting stomach is likely to be completely empty. There is no statistical difference between the effects of the different premedications on the stomach residue.

TABLE II-Gastric Residues Assessed in Increments of $5 \mathrm{ml}$

\begin{tabular}{c|c|c|c|c}
\hline $\begin{array}{c}\text { No } \\
\text { Prcmedication }\end{array}$ & Atropine & $\begin{array}{c}\text { Pethidine/Promethazine } \\
\text { and Atropine }\end{array}$ & $\begin{array}{c}\text { Papaveratum } \\
\text { and Hyoscine }\end{array}$ & Diazepam \\
\hline 0 & 5 & 0 & 50 & 25 \\
0 & 0 & 95 & 25 & 0 \\
0 & 50 & 0 & 0 & 0 \\
0 & 0 & 50 & 0 & 0 \\
10 & 30 & 0 & 40 & 25 \\
0 & 0 & 75 & 0 & 0 \\
0 & 45 & 0 & 0 & 0 \\
0 & 0 & 0 & 0 & 25 \\
0 & 80 & 15 & 30 & 25 \\
0 & 0 & 0 & & \\
\hline
\end{tabular}

All patients (aged 16 to 60 ) fasting and without water for at least four hours, lying on right side for at least one hour before assessment, judged fit. 


\section{Discussion and Clinical Application}

Metoclopramide in the absence of anticholinergic drugs has been shown by Jacoby and Brodie (1967) and Eisner (1968) to effect an increase in gastric motility causing gastric emptying. In the present study the drug given by mouth has been shown to empty moderate water residues in stomachs to a degree found in fasting subjects premedicated with diazepam. The drug may be administered intravenously or intramuscularly as well as taken by mouth, and using the intravenous route G. H. Griffiths (personal communication, 1969), exploiting radioisotope techniques, showed that it decreases the emptying time of solid meals into the duodenum.

We confirm that barium swallow radiography is a reliable method of assessment of stomach content and recommend this investigation for patients in whom there is doubt about the condition of the stomach. It has become our practice to perform barium swallow radiography on all trauma patients presenting for surgery requiring general anaesthesia. In some cases we have found that patients succumbing to trauma and who had recently eaten food have been shown by a barium swallow to have empty stomachs. In these circumstances delaying anaesthesia for the traditional four-hour period from the last oral intake is unnecessary, and, furthermore, non-emergency anaesthetic techniques may be used with confidence and safety.

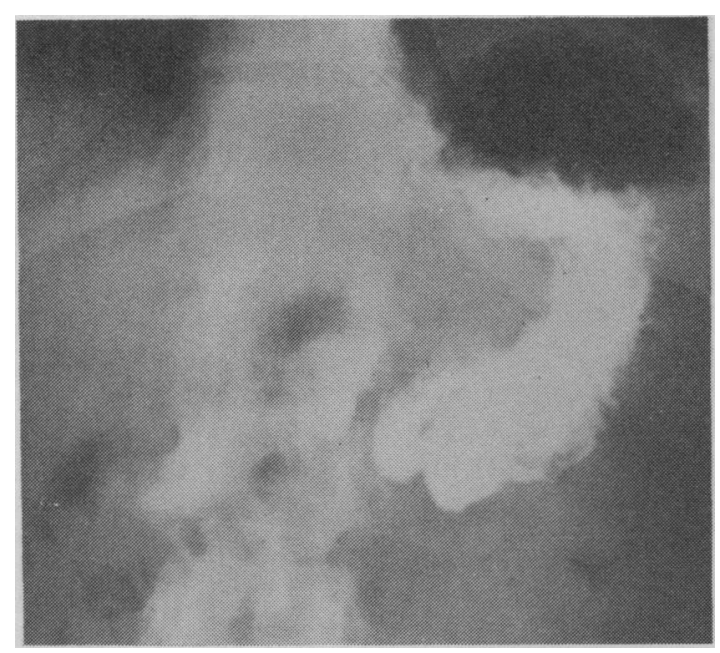

FIG. 4-Stomach containing "light meal."

When stomach residues are present $20 \mathrm{mg}$ of metoclopramide is given intravenously which effects emptying of the stomach contents into the duodenum in $\mathbf{3 0}$ minutes when the ingested meal was "light"- coffee and biscuits, etc. (see Figs. 4 and 5). When "heavier" meals have been taken, consisting of a bacon sandwich, two rolls, and three cups of tea, complete emptying took about one and a quarter hours after the metoclopramide.
Radiographs are taken at half-hourly intervals until the pictures show a mucosal pattern only in the stomach, which is associated with barium distribution well down the small intestine.

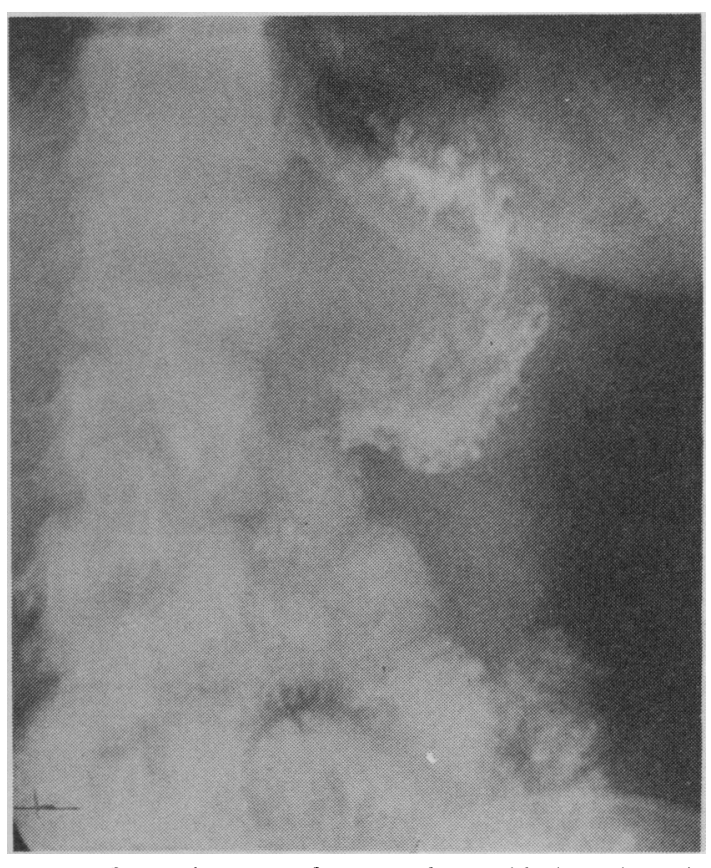

Another study (Kreel, et al., 1971) has confirmed the present finding that metoclopramide is effective by mouth in causing gastric emptying, and we suggest that its combination with oral premedication will reduce the potential hazard of regurgitation. As we have also found significant gastric residues in fasting patients receiving several types of premedication for routine surgery it seems worth while considering the use of the drug as an accompaniment to these premedicating agents, provided that atropine-like additions are not judged necessary. In the current anxiety expressed over maternal deaths (British Medical fournal, 1970) the place of metoclopramide in the pre-anaesthetic management of obstetric patients needs urgent investigation to confirm our hope of reducing regurgitation and vomit hazard which continues to be a significant cause of death.

We are at present conducting a study of stomach emptying rates in the traumatized patient, comparing timings in patients receiving either metoclopramide or a placebo by injection in order to confirm the therapeutic value of the drug in this area.

\section{References}

British Medical fournal, 1970, 2, 437

Eisner, M. (1968). British Medical fournal, 4, 679

Elliott, C. J. R., Sheville, E. (1968). Anaesthesia, 23, 33

Jacoby, H. I., and Brodie, D. A. (1967). Gastroenterology, 52, 676 Kreel, L., Trott, M., and Howells, T. H. (1971). Clinical Radiology. In press. 